\title{
BMJ Open A randomised placebo-controlled double-blind trial to assess the safety of intramuscular administration of allogeneic mesenchymal stromal cells for digital ulcers in systemic sclerosis: the MANUS Trial protocol
}

Femke C C van Rhijn-Brouwer, ${ }^{1}$ Hendrik Gremmels, ${ }^{1}$ Joost O Fledderus, ${ }^{1}$ Arnold H Schuurman, ${ }^{2}$ Femke Bonte-Mineur, ${ }^{3}$ Madelon C Vonk, ${ }^{4}$ Alexandre E Voskuyl, ${ }^{5}$ Jeska K de Vries-Bouwstra, ${ }^{6} \mathrm{~J}$ Henk Coert, ${ }^{2}$ Timothy R D J Radstake, ${ }^{7}$ Jacob M van Laar, ${ }^{7}$ Marianne C Verhaar, ${ }^{1}$ the MANUS Study Group

To cite: van Rhijn-Brouwer FCC, Gremmels H, Fledderus J0, et al. A randomised placebocontrolled double-blind trial to assess the safety of intramuscular administration of allogeneic mesenchymal stromal cells for digital ulcers in systemic sclerosis: the MANUS Trial protocol. BMJ Open 2018;8:e020479. doi:10.1136/ bmjopen-2017-020479

- Prepublication history for this paper is available online. To view these files, please visit the journal online (http://dx.doi. org/10.1136/bmjopen-2017020479).

Received 7 November 2017 Revised 10 July 2018 Accepted 13 July 2018

Check for updates

(C) Author(s) (or their employer(s)) 2018. Re-use permitted under CC BY-NC. No commercial re-use. See rights and permissions. Published by BMJ.

For numbered affiliations see end of article.

Correspondence to

Professor Marianne C Verhaar; m.c.verhaar@umcutrecht.nl

\section{ABSTRACT}

Introduction Systemic sclerosis (SSc) is an autoimmune disease characterised by inflammation, fibrosis and vasculopathy. Digital ulcers (DUs) are a frequent manifestation of vasculopathy in patients with SSc. Despite recent advances in pharmacological treatments, DU still have major health and economic implications. As there is currently no proven therapeutic strategy to promote DU healing, new treatments are urgently needed. Mesenchymal stem or stromal cells (MSCs) may provide a novel therapy for DU in SSc, because of their immunomodulatory and vasculoregenerative properties. Allogeneic MSC therapy involves functionally competent MSCs from healthy donors and may be used as 'offthe-shelf' available treatment. This study will evaluate whether allogeneic MSC therapy is a safe and potentially efficacious treatment for DU of SSc.

Methods and analysis The MANUS (Mesenchymal stromal cells for Angiogenesis and Neovascularization in digital Ucers of Systemic Sclerosis) Trial is a double-blind randomised placebo-controlled trial. 20 patients with SSc with refractory DU will be randomised to receive eight intramuscular injections with either placebo or $50^{\star} 10^{6}$ MSCs. The primary outcome is the toxicity of the treatment at 12 weeks after administration. Secondary outcomes include (serious) adverse events, number and time to healing of DU, pain, reported hand function, quality of life and SSc disease activity. We will also evaluate changes in nailfold capillaroscopy pattern, as well as biochemical parameters and biomarkers in peripheral blood and skin biopsies. Follow-up visits will be scheduled at 48 hours and 2, 4, 8, 12, 24 and 52 weeks post-treatment. If the results confirm safety, feasibility and potential efficacy, a large multicentre randomised controlled trial with longer follow-up will be initiated focusing on efficacy.

Ethics and dissemination The study has been approved by the Dutch Central Committee on Research Concerning Human Subjects (protocol no: NL51705.000.15). The
Strengths and limitations of this study

The MANUS Trial is the first double-blind randomised controlled trial to assess the safety and potential efficacy of mesenchymal stromal cells (MSCs) for digital ulcers.

- Intramuscular injection protocol to maximise safety.

- Results can inform effect size and sample size considerations for future trials using MSCs.

- Low sample size of this pilot trial requires larger follow-up trial to assess efficacy.

results will be disseminated through patient associations and conventional scientific channels.

Trial registration number NCT03211793; Pre-results.

\section{INTRODUCTION}

Systemic sclerosis (SSc) is a rare multisystem autoimmune connective tissue disease with high morbidity and mortality. The exact aetiology and pathogenesis of SSc are unknown, but involve small-vessel vasculopathy, immune dysregulation with production of autoantibodies and progressive fibrosis of the skin and major internal organs. This contributes to a 10 -year mortality of $~ 30 \%{ }^{1}$ Microvascular vasculopathy occurs early in the pathogenesis of SSc. ${ }^{2}$ Such vasculopathy can be found in many organs, contributes to end-organ damage and may give rise to severe complications. Skin vasculopathy results in chronic tissue hypoperfusion and hypoxia, and ultimately ischaemic manifestations such as digital ulcers. 
Digital ulcers are a serious problem in SSc, occurring in $30 \%$ to $50 \%$ of patients with SSc. ${ }^{34}$ These ulcers are very painful and heal slowly with scarring and digital resorption, which causes substantial functional disability. ${ }^{56}$ Infections in ulcers may also occur and can lead to gangrene and amputation of the extremities. ${ }^{7}$ Unfortunately, the available treatment options do not increase ulcer healing or are not effective in a significant proportion of patients.

The European League Against Rheumatism guideline recommends intravenous iloprost, bosentan or phosphodiesterase-5 inhibitors (PDE-5i) for the management of patients with digital ulcerations. ${ }^{8}$ Intravenous iloprost, the first-line treatment for digital ischaemia in SSc, has been shown to reduce ulcers by $50 \%$ in at most $28 \%$ of treated patients in a randomised placebo-controlled trial. ${ }^{9}$ Bosentan, an endothelin-1 receptor antagonist, has been shown to reduce new ulcer occurrence in two double-blind placebo-controlled trials, ${ }^{10}{ }^{11}$ but no effect on ulcer healing has been reported so far, apart from a 'trend toward efficacy' in a small uncontrolled trial. ${ }^{12}$ Similarly, while PDE-5i have shown promising results in healing digital ulcers, in a recent double-blind randomised controlled trial (RCT), $18 \%$ of the patients in the PDE-5i arm did not show ulcer healing. ${ }^{13}$

The lack of curative options for patients with digital ulcers underscores the urgent clinical need for a novel, targeted treatment that reduces vascular complications and inflammation, halts fibrosis and prevents disease progression. ${ }^{1415}$

Mesenchymal stem—or stromal—cells (MSCs) may be an effective treatment for digital ulcers caused by SSc, as MSCs have potent vasculoregenerative and immunomodulatory properties. MSCs are a subpopulation of bone marrow cells that can differentiate into various mesenchymal cell types (chondrocytes, osteocytes, adipocytes) under specific in vitro conditions. ${ }^{16}$ In vitro and in vivo studies have demonstrated that intramuscular administration of MSCs improves wound healing through promotion of angiogenesis and modulation of the locoregional immune response. Studies in mice demonstrated that intramuscular injected MSCs improve neovascularisation after ablation of the femoral artery (hind limb ischaemia model). ${ }^{17}$ MSCs were shown in vivo to secrete vascular endothelial growth factor, basic fibroblast growth factor and other cytokines, growth factors and chemokines in the murine hind limb ischaemia model, showing that MSCs are capable of paracrine interaction with a wide range of cells: immune cells, fibroblasts, endothelial cells and so on. ${ }^{18} 19$ Further in vitro studies have identified direct cell-to-cell interactions between MSCs, local tissue cells and various immune cells which potentiate the action of MSC-secreted factors. ${ }^{20-25}$ In vivo administration of MSCs leads to increased recruitment of macrophages and endothelial cells, and a reduction of effector T cells, suggesting possible mechanisms of action for the angiogenic and regenerative properties of MSCs. ${ }^{26-28}$

Subsequent small randomised placebo-controlled clinical trials in critical limb ischaemia showed favourable results of intramuscular autologous bone marrow-derived MSC therapy compared with standard care in patients with non-healing ulcers. ${ }^{29}{ }^{30}$ MSC injection was more effective than mononuclear cell (MNCs) injection in critical limb ischaemia and non-healing ulcers of patients with diabetes, which confirms results from preclinical studies. ${ }^{31} 32$

Administration of allogeneic MSC was also effective in critical limb ischaemia and no treatment-related adverse events were observed. Intramuscular injection of allogeneic umbilical cord blood-derived MSC in four patients with limb ischaemia related to Buerger's disease led to increased capillary formation and reduction in pain. There were no adverse events. ${ }^{33}$ In a randomised placebo-controlled trial using allogeneic MSCs as treatment for critical limb ischaemia, an increase in ankle-brachial index and ankle pressure in the group treated with MSCs was seen. There were no treatment-related adverse events. $^{34}$

Though there is considerable heterogeneity in the used cell types and administration protocols, these clinical studies in critical limb ischaemia suggest that injection of cell depots in patients with SSc may be a viable possible treatment for digital ulcers caused by SSc. Small uncontrolled studies in SSc show that injection of various autologous cells was well tolerated and did not lead to adverse events; however, local administration of cultured MSCs has not yet been assessed in this condition..$^{35}$ Interestingly, two case reports that describe intravenous administration of respectively autologous or allogeneic MSCs report a marked effect on ulcer healing, reduction of skin fibrosis and promotion of new vessel formation. There were no adverse events associated with MSC administration. ${ }^{36}{ }^{37} \mathrm{In}$ addition to the studies in critical limb ischaemia and SSc, the safety and efficacy of allogeneic MSC administration has been established in a variety of conditions, including autoimmune disease. No acute or chronic local tissue reactions to the allogeneic cells have been reported. ${ }^{38-41}$ Consequently, there are no safety concerns that would preclude a clinical trial that assesses allogeneic MSCs as a treatment option for refractory digital ulcers in SSc. However, the safety and feasibility of intramuscularly injected MSCs in SSc should be confirmed before initiation of a larger trial that is sufficiently powered to assess efficacy is possible. Therefore, the next logical step in the development of a treatment option for SSc is to assess the safety, feasibility and possible efficacy of intramuscular administration of allogeneic MSCs in a randomised, placebo-controlled, double-blind fashion.

Here, we describe the protocol and the rationale for the MANUS (Mesenchymal stromal cells for Angiogenesis and Neovascularization in digital Ulcers of Systemic Sclerosis) Trial. The MANUS Trial is an investigator-initiated phase IIa/b randomised placebo-controlled doubleblind trial, in which we will evaluate the safety, feasibility and potential efficacy of intramuscular administration of allogeneic MSCs as treatment for digital ulcers caused by SSc. If the results confirm safety, feasibility and show 
Table 1 Inclusion and exclusion criteria

\begin{tabular}{|c|c|}
\hline Inclusion criteria & Exclusion criteria \\
\hline & $\begin{array}{l}\text { Ulcer with underlying } \\
\text { calcinosis (ruled out by } \\
\text { X-ray prior to screening/ } \\
\text { inclusion) }\end{array}$ \\
\hline Age $>18$ years & $\begin{array}{l}\text { History of neoplasm or } \\
\text { malignancy in the past } \\
10 \text { years }\end{array}$ \\
\hline $\begin{array}{l}\text { Established diagnosis of SSc } \\
\text { according to the } 2013 \text { ACR/EULAR } \\
\text { criteria }\end{array}$ & $\begin{array}{l}\text { Pregnancy or unwillingness } \\
\text { to use adequate } \\
\text { contraception during study }\end{array}$ \\
\hline $\begin{array}{l}\text { At least one active digital ulcer } \\
\text { (painful area, }>2 \mathrm{~mm} \text { in diameter } \\
\text { with visible depth and loss of } \\
\text { dermis) refractory to intravenous } \\
\text { prostacyclins: } \\
\text { Refractory to prostacyclins is } \\
\text { defined as } \\
\text { - Worsening of ulcer(s) within } \\
1 \text { month after intravenous } \\
\text { prostacyclins } \\
\text { - No improvement of ulcer(s) } \\
\text { after } 2 \text { months after } \\
\text { intravenous prostacyclins, } \\
\text { as judged by the referring } \\
\text { physician } \\
\text { - Recurrence of exactly the } \\
\text { same ulcer(s) (same location) } \\
\text { within } 3 \text { months after } \\
\text { intravenous prostacyclins }\end{array}$ & $\begin{array}{l}\text { Serious known } \\
\text { concomitant disease with } \\
\text { life expectancy }<1 \text { year }\end{array}$ \\
\hline \multirow[t]{3}{*}{ Written informed consent } & Uncontrolled hypertension \\
\hline & $\begin{array}{l}\text { Uncontrolled acute or } \\
\text { chronic infection with } \\
\text { systemic symptoms (eg, } \\
\text { fever) }\end{array}$ \\
\hline & Follow-up impossible \\
\hline
\end{tabular}

ACR, American College of Rheumatology; EULAR, European League Against Rheumatism; SSc, systemic sclerosis.

potential beneficial effects of the intervention regarding clinical parameters, a large multicentre RCT with longer follow-up will be initiated focusing on efficacy.

\section{METHODS AND ANALYSIS \\ Design}

The MANUS Trial is a phase IIa/b randomised doubleblind placebo-controlled trial.

We will include 20 patients with SSc who satisfy the inclusion criteria (table 1). Inclusion and exclusion criteria were designed to select patients with refractory ulcers who are in a reasonable health condition to allow trial participation. Study participants will be recruited from our own SSc outpatient population as well as in collaboration with other scleroderma expert centres, who will refer patients to the University Medical Center Utrecht. Baseline characteristics will be collected, including parameters that were shown to predict ulcer healing in observational cohorts, ${ }^{42} 43$ as well as skin scoring and capillaroscopy to assess severity and stage of SSc. A safety assessment including physical examination, laboratory studies, ECG and urine evaluation will be performed (see table 2 and figure 1). We anticipate to be able to commence enrolment in November 2018.

Participants will be randomised in blocks by the Department of Clinical Pharmacy using a computerised table, with the block size unknown to the investigators. The treatment allocation will be implemented by the Cell Therapy Facility, with no communication of allocation status to the investigational team. Both investigators and participants will be blinded to treatment allocation by the use of a verum and a placebo product that are similar in appearance. In case of an emergency, deblinding can be performed by the Department of Pharmacy.

The inclusion of a placebo control arm in the design of the MANUS Trial despite the relatively low number is important to properly evaluate feasibility, safety and secondary efficacy outcomes. A two-armed design will enable us to assess whether patients are willing to participate if a placebo arm is present. The possibility of randomisation can have a major impact on participant accrual; for instance, in the reJUVenating ENdothelial progenitor cells via Transcutaneous intra-Arterial Supplementation (JUVENTAS trial), one-third of potentially eligible patients was excluded due to unwillingness to participate in a randomised trial, even though this represented a 'no option' population who had no other alternatives than conservative management or amputation. $^{44}$

Many of the secondary efficacy outcomes and some of the safety outcomes in the proposed study incorporate a degree of subjectivity and are therefore subject to bias from both patients and assessors. Given the considerable placebo effect that can be observed in trials assessing 'stem cell treatments', blinding of both clinicians as well as participants is of paramount importance. For instance, in MNC therapy for cardiac disease, early uncontrolled trials showed an effect, whereas later, more rigorously designed RCTs did not show an effect, despite the relatively robust outcome measures used. ${ }^{45}$

Additionally, we will be able to determine whether the used blinding procedures are effective at masking treatment allocation. No such formal evaluation exists for intramuscular placebo injections of a cellular product in contrast to pharmacological placebos, which are much better characterised.

Ethical concerns of stem cell therapy due to subjecting the placebo group to an invasive sham procedure were previously explored by our group. ${ }^{46}$ The risk of complications is considered to be very low, based on studies that already explored intramuscular administration of MSCs in various settings as described previously. Should complications arise, the placebo control will help attributing these to the MSC product or the intramuscular injections per se. Furthermore, as there is no alternative treatment for patients with digital ulcers refractory to intravenous prostanoids, patients are not withheld regular care. 
Table 2 SPIRIT schedule of study visits and study procedures

Baseline Week 0 48hours Week 2 Week 4 Week 8 Week 12 Week 24 Week 52

\begin{tabular}{|c|c|c|c|c|c|c|c|c|c|}
\hline Informed consent & $x$ & & & & & & & & \\
\hline mRSS & $x$ & & & & & & $x$ & $x$ & $x$ \\
\hline Pictures of hands & $x$ & $x$ & $x$ & $x$ & $x$ & $x$ & $x$ & $x$ & $x$ \\
\hline $\mathrm{H} \& \mathrm{P}$ & $x$ & & $x$ & $x$ & $x$ & $x$ & $x$ & $x$ & $x$ \\
\hline Safety laboratory studies & $x$ & & $x$ & & & & $x$ & & \\
\hline Skin biopsy & $x$ & & & & & & $x$ & & \\
\hline Urine screening & $x$ & & $x$ & & & & $x$ & & \\
\hline Capillaroscopy & $x$ & & & $x$ & & & $x$ & $x$ & $\mathrm{x}$ \\
\hline ECG & $x$ & & & & & & $x$ & & \\
\hline
\end{tabular}

H\&P, history and physical examination; mRSS, modified Rodnan Skin Score; SPIRIT, Standard Protocol Items: Recommendations for Interventional Trials.

There are also no restrictions on the treatment patients may receive prior to participation.

\section{Intervention}

Investigational medicinal product

In this study, allogeneic MSCs will be used. Use of autologous cells seems preferable for immunological reasons,

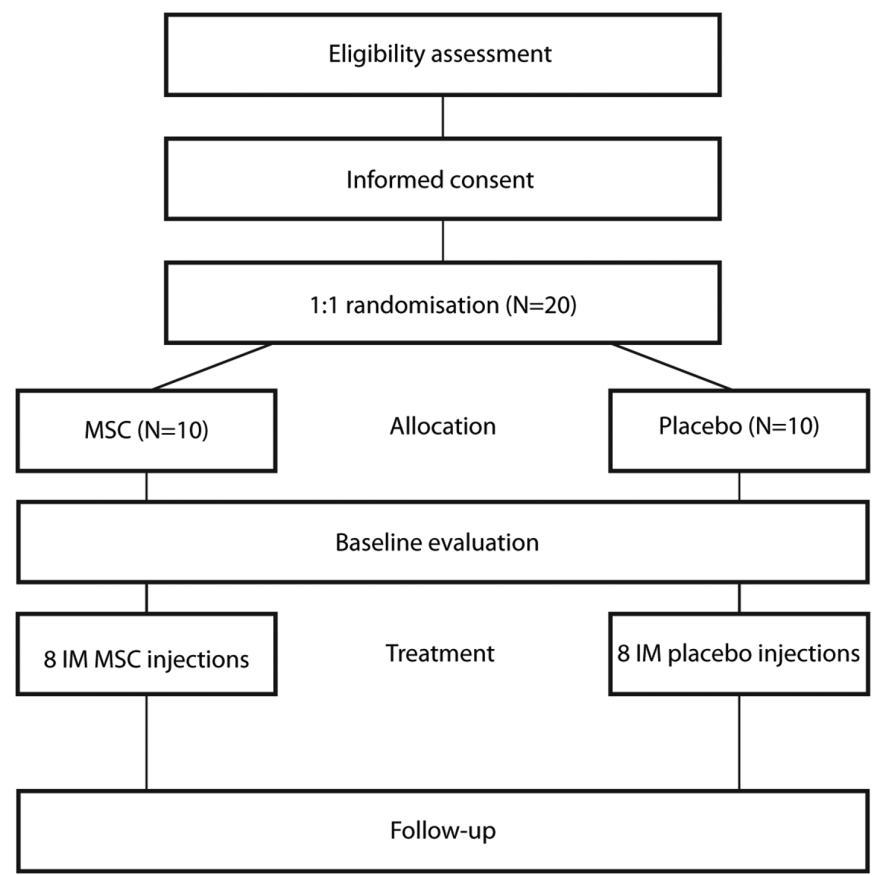

Figure 1 CONSORT study flow diagram of the MANUS Trial. See table 2 for the schedule of study visits and the assessments conducted at each visit. CONSORT, Consolidated Standards of Reporting Trials; IM, intramuscular; MANUS, Mesenchymal stromal cells for Angiogenesis and Neovascularization in digital Ulcers of Systemic Sclerosis; MSC, mesenchymal stem cell. as enhanced clearance of allogeneic cells has been suggested, possibly through formation of alloreactive antibodies. ${ }^{47}$ However, the use of autologous cells may have disadvantages, as MSCs obtained from patients with SSc may have reduced vasculoregenerative properties and may have been affected by disease. SSc MSCs display a different phenotype compared with MSCs from healthy controls and have a reduced capacity to differentiate into endothelial cells. ${ }^{48}{ }^{49}$ MSCs from patients with SSc also overexpress proangiogenic and profibrotic factors. ${ }^{50}$ They also express more transforming growth factor beta (TGF- $\beta$ ) type II receptors and produce more collagen- $\alpha 2$ mRNA on TGF- $\beta$ stimulation, a pathway implicated in the development of fibrosis. ${ }^{51}$ Preclinical studies with timed chemotherapeutic ablation of MSCs have shown that permanent integration of MSCs is not required for sustained therapeutic effects. ${ }^{52}$ In a patient population where aberrant fibroblastic differentiation and fibrosis are theoretical risks, enhanced clearance of the allograft are likely even desirable. Lastly, the use of autologous MSCs requires bone marrow aspiration and cell culture, which is an additional burden for the patient, increases costs and delays treatment. ${ }^{53}$

The MSCs to be used in this study (product name: MSC, marrow) are harvested from bone marrow donated by voluntary donors. Donors are screened for infectious diseases as indicated by the Wet Veiligheid en Kwaliteit Lichaamsmaterialen, the transposition into Dutch law of the European Union directive 2006/17. MSCs are expanded and processed by the University Medical Center Utrecht Good Manufacturing Practice (GMP) certified Cell Therapy Facility. After harvesting, the cells are expanded ex vivo in alpha-minimum essential medium containing $5 \%$ human platelet lysate. Before release, the product is tested for bacterial/fungal contamination and 
endotoxins. MSCs were expanded ex vivo until passage 3 and cryopreserved until use. Cells from two different donors will be used. The product to be administered to patients will be thawed on the day of treatment, washed to remove the cryopreservant dimethyl sulfoxide and resuspended in $\mathrm{NaCl} 0.9 \%$ containing $10 \%$ human serum albumin. The placebo will consist of $\mathrm{NaCl} 0.9 \%$ and $10 \%$ human serum albumin. Syringes will be blinded.

\section{Route of administration and injection sites}

The intramuscular route for MSC administration will be used. Currently, there are no clinical studies in upper limb ischaemia that compare the safety and efficacy of the various administration routes and locations. However, there are indications that intramuscular administration is superior to intravascular administration.

First, in patients with vascular complications of SSc, the peripheral perfusion is compromised by the very nature of their disease. Intramuscular administration bypasses this problem altogether by delivering the cells closer to the ulcer site. Second, muscle tissue supports intramuscular-injected MSCs with nutrients and oxygen, which benefits the survival and in vivo functions of MSC. ${ }^{54}$ Thirdly, intramuscular injection may also be safer in patients with SSc, as intravenous administration in both preclinical and clinical studies has been shown to lead to entrapping of MSCs in the lungs. ${ }^{556}$ While no pulmonary embolism or other pulmonary pathology were reported in clinical studies conducted so far, pulmonary trapping of MSC seems less desirable in a patient population at risk for pulmonary pathology, such as patients with SSc.

Previous preclinical and clinical studies using the intramuscular route, in which MSC were administered as treatment for patients with critical limb ischaemia and/or non-healing ulcers, show that the treatment was well-tolerated and there was no evidence for local or systemic toxicity, as we discussed above. ${ }^{17} 313334$ Additionally, a number of clinical studies using cellular products for critical limb ischaemia in the upper limb have applied the intramuscular administration route with success. ${ }^{57-59}$

Clinical studies in patients with ischaemia or ulcers of the lower extremity in which cells were injected intramuscularly report injection sites both close to and at a distance from the ulcers. Only very few studies reported on local injections in the upper extremity and protocols differed widely with regard to the location and the number of injections. On assessing these protocols, we found that in some instances it can be questioned whether these were true intramuscular injections, or the injection sites were close to essential structures which might pose a safety risk, or the location would provide insufficient space to harbour an injected volume.

Based on the available data, the superiority of intramuscular MSC administration in animal models, and given that it is unknown which injections are most effective (at a distance vs local), we designed an injection protocol that combines both distant intramuscular injection sites as well as intramuscular injection sites closer to the fingers; $2 \times$ forearm, $4 \times \mathrm{mm}$ interossei, thenar and hypothenar musculature- eight injections in total (see figure 2).

\section{Dose}

Fiftymillion allogeneic MSCs divided in eight doses of $0.5 \mathrm{~mL}$ or $1 \mathrm{~mL}$ ( $1 \mathrm{~mL}$ : forearm; $0.5 \mathrm{~mL}$ : hand injections) will be administered.

MSC doses in clinical trials for critical limb ischaemia of the lower limb ranged from $1 * 10^{6}$ to $900 * 10^{6} .{ }^{3133}$ To reduce the risk of injection-related complications, we have decided to use fewer injection sites compared with other studies in which cells are injected into the upper extremity. This number of sites limits the amount of cells that can be injected. At a total dose of $50 * 10^{6}$ cells, our dose is in the lower range. Animal and human studies with a dosefinding component have previously shown that high cell doses do not necessarily lead to better efficacy, but even suggested an inverse dose-response effect. Cell crowding
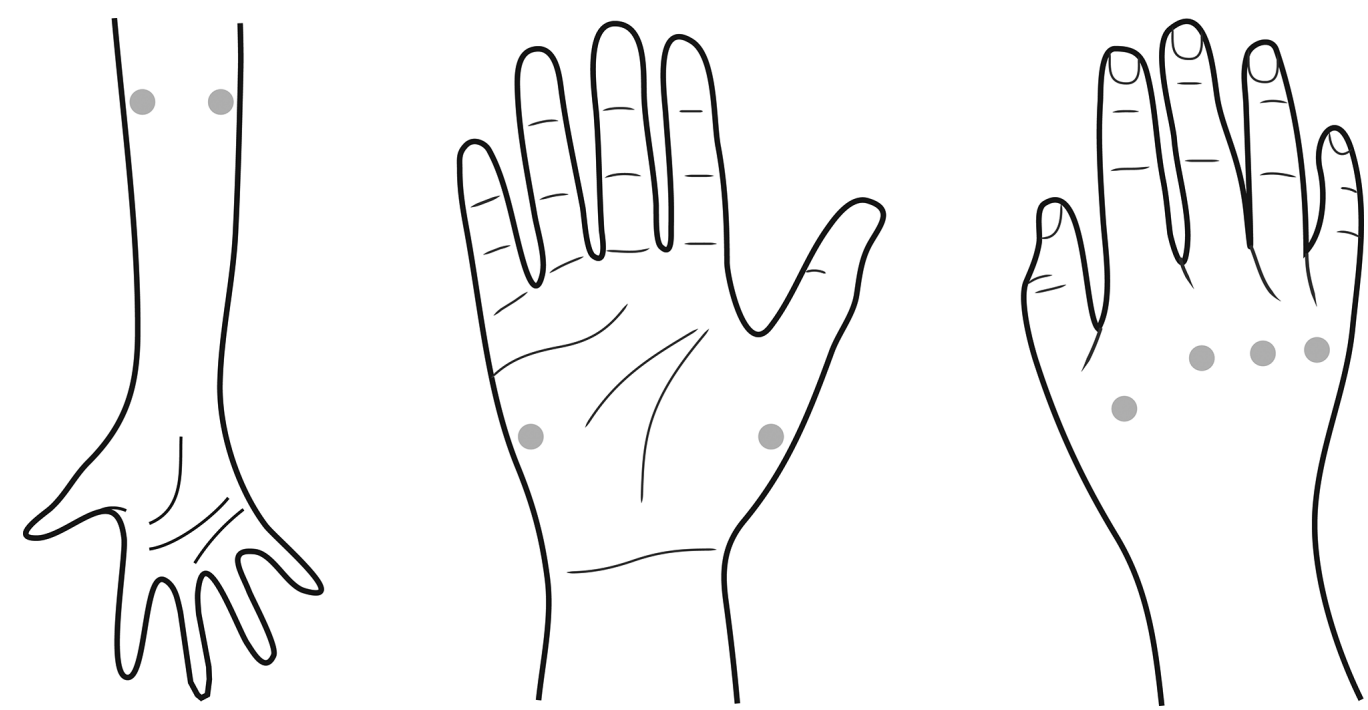

Figure 2 injection sites. Mesenchymal stem cells will be intramuscularly injected at these eight sites. 
is thought to play a role. ${ }^{385460}$ The number of MSCs per injection in our protocol does not exceed doses used in literature despite the reduction of injection sites.

\section{Supportive care and concomitant medication}

Non-pharmacological therapy and patient counselling regarding prevention of ulcers and ulcer care will be provided in accordance to the Systemic Sclerosis Care Pathway (Zorgpad Sclerodermie) of the Dutch Rheumatology Association. The need for surgical management will be assessed in consultation with/after evaluation by the hand surgeon of the trial team and in close collaboration with the patient's own rheumatologist.

We aim to avoid alterations to the medication regimen of patients during the trial. Drugs that can influence local perfusion should not be started between 4 weeks prior to MSC administration and 12 weeks after; dose changes are not allowed during this period. However, if it is deemed medically necessary, the medication regimen can be altered by the patient's own rheumatologist. This may include additional iloprost infusions or other therapy directed to digital ulcers. Medication use, including analgesic use, will be carefully documented.

\section{Outcomes and follow-up}

Follow-up appointments have been scheduled to allow early detection of possible adverse events and optimal evaluation of possible MSC-mediated effects through biomarkers, clinical change and objective change as detected with capillaroscopy and physical examination. Follow-up will be more frequent in the first 3 months, with the last follow-up visit 1 year after treatment to assess long-term safety.

The MANUS Trial will be overseen by the Internal Data Safety Monitoring Board (DSMB) of the University Medical Center Utrecht. This is an independent DSMB, consisting of clinicians (including an expert on scleroderma), a biostatistician and a clinical epidemiologist. Every 3 months, the DSMB will review the status and conduct of the clinical trial, evaluate all causes of death and adverse events and make recommendations to the clinical research group concerning the trial's continuation and modification.

\section{Safety}

The primary outcome is the toxicity of the treatment at 12 weeks after MSC administration, defined as

(1) local toxicity, including signs of local inflammation (swelling, warmth, impairment of function), worsening of ulcers or new ulcers or haematomas after MSC administration and (2) other adverse events, graded according to the Common Terminology Criteria for Adverse Events, version 4.0, expressed as maximum grade toxicity per organ system.

Secondary safety outcomes are the incidence of any serious adverse events (SAEs) at 12 weeks post-treatment, defined as events leading to hospitalisation, death or persistent or significant disability.

\section{Efficacy}

Evaluation of therapies for digital ulcers has been complicated by a lack of suitable outcomes. ${ }^{60}{ }^{61}$ To assess potentially relevant outcome measures for efficacy, we will use validated questionnaires for quality of life, hand function and detailed ulcer observations. Currently, the relation between the Scleroderma Health Assessment Questionnaire (S-HAQ) and other quality-of-life questionnaires and ulcer-related hand function is unsure-the only validated efficacy parameter for digital ulcer treatments in SSc is the number of ulcers and ulcer healing. ${ }^{62}$ In the MANUS Trial, we will therefore use these questionnaires to further explore the effect of digital ulcers on disability and quality of life.

Ulcer healing will be monitored both clinically and through sequential digital pictures. Pictures will be taken in a standardised and reproducible fashion. While manual measuring of ulcers has been shown to be unreliable, using digital pictures to measure ulcer size has been reported as a valid and reproducible method-digital pictures with a reference scale included were shown to be equally reliable and reproducible as tracing the ulcers on transparent material. ${ }^{6364}$

Nailfold capillaroscopy (NFC) is a reproducible non-invasive method to visualise the nailfold capillaries and assess microvascular morphology. Images will be scored both qualitatively as well as semiquantitatively, using standardised and previously validated methods. ${ }^{65} 66$ It has been shown that therapy directed to the microvasculature can lead to favourable changes in the NFC pattern in SSc, though it is uncertain when the effects will be first apparent. ${ }^{6768}$ Therefore, NFC will be conducted at 2,12 , 24 and 52 weeks.

While the study is not powered to assess efficacy, various outcome measures for efficacy will be assessed to assess their feasibility as an outcome as well as inform future power calculations. These outcome measures include change in patients-reported ulcer pain, quality of life as assessed with validated questionnaires (SF-36, S-HAQ, EQ5D), hand function as assessed with the Cochin Hand Function Scale, number of digital ulcers at 12 weeks, healing of ulcers at 12 weeks, area of digital ulcers, the need to alter the medication regimen during the study as determined by the patient's own rheumatologist, the severity of SSc as assessed with the Modified Rodnan Skin Score, severity of Raynaud's symptoms, changes in capillary morphology as visualised with video-assisted NFC, and changes in laboratory parameters including biomarkers for inflammation and endothelial (dys)function. Plasma, serum and peripheral blood MNCs will be sampled at baseline and 48 hours, 2, 4 and 12 weeks post-treatment, and a skin biopsy will be taken at baseline and at 12 weeks. For binary outcomes, the observed effect estimates and for continuous outcomes, the mean and SD can be used as a basis for future power calculations.

To determine which outcome would be most appropriate in the follow-up trial, an expert group will be consulted using a Delphi standardised consultation 
approach ${ }^{69}$ For each participant, it will be established whether ulcers have improved in the time period between inclusion and the primary endpoint. This expert judgement of 'improvement' or not will then be linked to the clinical outcome data that we collected within the trial. We will then assess whether there is a single outcome parameter that can define response or whether composite outcome would be preferred.

\section{Feasibility}

A larger trial will be deemed feasible if the treatment is safe, if recruitment for this trial can be completed within a reasonable time (12 months) and if treatment allocation can be successfully be concealed from clinicians and participants.

Treatment safety will be determined in close consultation with the DSMB. In case of SAEs related to the treatment, a follow-up trial will not be commenced. To establish the presence of a causal relationship to the study treatment, the WHO guideline for pharmacovigilance will be followed.

The rate of recruitment and willingness to participate in a trial that contains a placebo arm in this pilot will inform our decision regarding recruitment feasibility for a larger trial based on the calculated sample size and recruitment duration. As there will only be 10 patients in the treatment group, we understand that the incidence of adverse events in this trial may be a poor estimate of the expected incidence in a larger trial. If, however, there are any serious AEs definitely attributable to the treatment according to the WHO guidelines for pharmacovigilance, we will reconsider the definitive trial or its design.

Concealment of treatment allocation will be assessed by asking participants and clinicians in which arm they think the participant was, using a three-point scale ('verum', 'placebo' or 'don't know'). To gain a balanced view, this question will be posed at 12 weeks (primary endpoint) and at 52 weeks (conclusion of the trial). Data will be analysed using James' and Bang's Blinding index to determine the degree of blinding in the trial, within each arm and whether this deviates from random chance. ${ }^{70}$

\section{Statistical analyses}

The $N$ of 20 is based on the number of patients that we can realistically recruit from our own population and collaborating centres. This number will allow us to detect which, if any, SAEs may occur and will provide a rough estimate of effect size that may inform the design of future studies. To be able to determine statistically significant differences with regard to safety and efficacy, much larger groups will likely be needed. However, to be able to include such a number of patients, an international multicentre trial would need to be initiated. This would require more solid indications regarding the safety and potential efficacy of MSCs in SSc, as may be provided by the proposed study.

Data will be analysed on an intention-to-treat basis. Data regarding adverse events and SAEs will be provided using descriptive statistics and tables. Population characteristics will be provided using descriptive statistics. Comparisons between groups will be made using linear mixed models. For dichotomous outcomes, generalised mixed models or Kaplan-Meier curves and the log-rank test will be used where appropriate.

\section{Patient involvement}

The lack of effective treatments for digital ulcers and the subsequent impact on daily functioning and quality of life is a major unmet need for patients with SSc. Patient advocacy has led to incorporation of 'effect on digital ulcers' as a required outcome measure prior to European Medicines Agency registration of pharmaceuticals as treatment for SSc. The exploratory outcome measures in this trial also include patient reported outcomes (disability, quality of life) to fully capture the possible effects of MSC administration.

A patient advocate is part of the Trial End User Committee, which meets once a year and includes rheumatology experts, regenerative medicine experts and intellectual property advisors. The research protocol and the patient letter/informed consent form has been discussed with this patient advocate, who is a member of the NVLE (Dutch association for scleroderma, systemic lupus and MCTD). The NVLE has kindly agreed to post information (which has been ethically approved prior to publication) about the trial on their website. The results of the study will be disseminated to the study participants through a newsletter and a patient information day. The burden of the intervention has not been assessed by patients themselves.

\section{ETHICS AND DISSEMINATION}

The study will be conducted according to the principles of the Declaration of Helsinki (Adopted by the 18th World Medical Association (WMA) General Assembly, Helsinki, Finland, June 1964 and amended by the 64th WMA General Assembly, Fortaleza, Brazil, October 2013) and in accordance with the Dutch Medical Research Involving Human Subjects Act (WMO). The study has been approved by the Dutch Central Committee on Research Concerning Human Subjects (protocol number NL51705.000.15).

Participants will be informed about the study by their own rheumatologist. Individuals interested in participating will be asked for consent to share their contact details with the coordinating investigator. The coordinating investigator will contact the patient and provide verbal and written information, including the patient letter and informed consent form. These materials have been approved by the Dutch Central Committee on Research concerning Human Subjects. Participants do not have to respond within a set time frame, but at least 2 weeks ahead of the intended treatment date to allow time for preparation of the treatment. 
Participants can leave the study at any time for any reason if they wish to do so without any consequences. The investigator can decide to withdraw a participant from the study for urgent medical reasons.

After analysis of the data, the results will be disseminated to the relevant stakeholders, such as rheumatologists, patients with SSc and digital ulcers and scientists in the field of vascular and regenerative medicine. Dissemination will occur through presentations on scientific conferences and meetings, and through publication of articles in peer-reviewed and patient journals.

After publication of the main study results, data gathered in the trial will be made available. Individual deidentified participant data that underlie the reported results will be shared. Other documents that will made available are the study protocol, statistical analysis plan and the informed consent form. Data will be available immediately after publication to anyone who wishes to access the data. Data will be made available indefinitely and unrestrictedly at an online location to be determined.

\section{DISCUSSION}

In SSc, vascular complications are a major cause of morbidity, contribute to end-organ damage and have major impact on quality of life and healthcare costs. The efficacy and safety of MSC administration has been suggested in various conditions, including SSc. Local administration of various cell types for digital ulcers and/ or hand stiffness in SSc has been investigated in several small uncontrolled studies, in which BM-MNC or adipose tissue derived cells were used. ${ }^{35}$ These studies show that locoregional cell administration in the upper limb to treat digital ischaemia in SSc is safe and potentially effective. ${ }^{58}{ }^{71-76}$ Recent case reports that explored intravenous delivery suggest that administration of MSCs may be a worthwhile treatment option in SSc. However, controlled trials assessing the intramuscular administration route are lacking in SSc. Additionally, allogeneic BM-derived MSC therapy is attractive as it may be used as 'off-the-shelf' available treatment and uses functionally competent MSC from healthy donors.

Hence, the MANUS Trial aims to investigate the feasibility, safety and potential clinical effects of intramuscular injection of allogeneic BM-MSC in 20 patients with SSc with digital ulcers. If the results confirm safety and show potential beneficial effects of the intervention regarding clinical parameters, a large multicentre RCT with longer follow-up will be initiated focusing on efficacy.

Furthermore, the results of this study may provide a basis for studies in other groups of patients with vascular and/or autoimmune diseases. The extensive vascular damage and loss of neovascularisation and vascular regeneration makes SSc a relevant 'model disease' to study new therapeutic regenerative strategies aimed at therapeutic neovascularisation. ${ }^{77}$ If we observe beneficial immunomodulatory effects this may provide a basis for further studies in SSc but also in other autoimmune diseases.
On the other hand, if we observe no demonstrable effect on clinical or laboratory parameters of vasculopathy this also has important clinical relevance, as currently patients receive (commercial) stem cell therapy for many disorders while no adequate well-controlled studies have demonstrated safety or efficacy. ${ }^{78}$ The MANUS Trial is thus an important step towards evidence-based MSC treatment for digital ulcers in SSc.

\section{Author affiliations}

${ }^{1}$ Department of Nephrology and Hypertension, University Medical Center Utrecht, Utrecht, The Netherlands

${ }^{2}$ Department of Plastic Reconstructive and Hand Surgery, University Medical Center Utrecht, Utrecht, The Netherlands

${ }^{3}$ Department of Rheumatology, Maasstad Ziekenhuis, Rotterdam, The Netherlands ${ }^{4}$ Department of Rheumatology, Radboud University Medical Center, Nijmegen, The Netherlands

${ }^{5}$ Amsterdam Rheumatology and Immunology Center, VU University Medical Center (VUmc), Amsterdam, The Netherlands

${ }^{6}$ Department of Rheumatology, Leiden University Medical Center, Leiden, The Netherlands

${ }^{7}$ Department of Rheumatology and Clinical Immunology, University Medical Center Utrecht, Utrecht, The Netherlands

Acknowledgements We thank J Welling for his involvement and input in the Trial End User Committee as a patient advocate.

Collaborators F C C van Rhijn-Brouwer, H Gremmels, J 0 Fledderus, A H Schuurman, S Zeddies, I C M Slaper-Cortenbach, M J H de Hair, A C A Marijnissen, J Tekstra, E Ton, P M J Welsing, F Bonte-Mineur, M C Vonk, A E Voskuyl, J K de VriesBouwstra, J H Coert, T R D J Radstake, J M van Laar, M C Verhaar.

Contributors JMvL, TRDJR and MCV conceived the study. FCCvR-B, HG, JOF, AHS, FB-M, MCV, AEV, JKdV-B, JHC, TRDJR, JMvL and MCV designed the study protocol. FCCvR-B, HG, JOF, JMvL and MCV drafted this manuscript. FCCvR-B, HG, JOF, AHS, FB-M, MCV, AEV, JKdV-B, JHC, TRDJR, JMvL and MCV critically revised the manuscript. FCCvR-B, HG, JOF, AHS, FB-M, MCV, AEV, JKdV-B, JHC, TRDJR, JMvL and MCV read and approved the final manuscript.

Funding The MANUS Trial is funded by a ZonMw Translational Adult Stem Cell Research Programme grant (no: 116003005).

Competing interests JMvL received honoraria from Arthrogen, BMS, Eli Lilly, Janssen, MSD, Pfizer, Roche, and research grants from Astra Zeneca, Genentech, MSD.

\section{Patient consent Not required.}

Ethics approval Ethical approval for the MANUS Trial was granted by the Dutch Central Committee for Research on Human subjects (protocol no: NL51705.000.15).

Provenance and peer review Not commissioned; externally peer reviewed.

Open access This is an open access article distributed in accordance with the Creative Commons Attribution Non Commercial (CC BY-NC 4.0) license, which permits others to distribute, remix, adapt, build upon this work non-commercially, and license their derivative works on different terms, provided the original work is properly cited, appropriate credit is given, any changes made indicated, and the use is non-commercial. See: http://creativecommons.org/licenses/by-nc/4.0/.

\section{REFERENCES}

1. Al-Dhaher FF, Pope JE, Ouimet JM. Determinants of morbidity and mortality of systemic sclerosis in Canada. Semin Arthritis Rheum 2010;39:269-77.

2. Rabquer BJ, Koch AE. Angiogenesis and vasculopathy in systemic sclerosis: evolving concepts. Curr Rheumatol Rep 2012;14:56-63.

3. Ferri C, Valentini G, Cozzi F, et al. Systemic sclerosis: demographic, clinical, and serologic features and survival in 1,012 Italian patients. Medicine 2002;81:139-53.

4. Steen V, Denton CP, Pope JE, et al. Digital ulcers: overt vascular disease in systemic sclerosis. Rheumatology 2009;24:iii19-24. 
5. Mouthon L, Carpentier PH, Lok C, et al. Ischemic digital ulcers affect hand disability and pain in systemic sclerosis. $J$ Rheumatol 2014;41:1317-23.

6. Bérezné A, Seror R, Morell-Dubois S, et al. Impact of systemic sclerosis on occupational and professional activity with attention to patients with digital ulcers. Arthritis Care Res 2011;63:277-85.

7. Schiopu E, Impens AJ, Phillips K. Digital ischemia in scleroderma spectrum of diseases. Int $J$ Rheumatol 2010;2010:1-8.

8. Kowal-Bielecka O, Landewé R, Avouac J, et al. EULAR recommendations for the treatment of systemic sclerosis: a report from the EULAR Scleroderma Trials and Research group (EUSTAR). Ann Rheum Dis 2009;68:620-8.

9. Wigley FM, Wise RA, Seibold JR, et al. Intravenous iloprost infusion in patients with Raynaud phenomenon secondary to systemic sclerosis. A multicenter, placebo-controlled, double-blind study. Ann Intern Med 1994;120:199-206.

10. Matucci-Cerinic M, Denton CP, Furst DE, et al. Bosentan treatment of digital ulcers related to systemic sclerosis: results from the RAPIDS-2 randomised, double-blind, placebo-controlled trial. Ann Rheum Dis 2011;70:32-8.

11. Korn JH, Mayes M, Matucci Cerinic M, et al. Digital ulcers in systemic sclerosis: prevention by treatment with bosentan, an oral endothelin receptor antagonist. Arthritis Rheum 2004;50:3985-93.

12. García de la Peña-Lefebvre $P$, Rodríguez Rubio $S$, Valero Expósito $\mathrm{M}$, et al. Long-term experience of bosentan for treating ulcers and healed ulcers in systemic sclerosis patients. Rheumatology 2008;47:464-6.

13. Hachulla E, Hatron PY, Carpentier P, et al. Efficacy of sildenafil on ischaemic digital ulcer healing in systemic sclerosis: the placebocontrolled SEDUCE study. Ann Rheum Dis 2016;75:1009-15.

14. Herrick AL. Management of Raynaud's phenomenon and digital ischemia. Curr Rheumatol Rep 2013;15:303.

15. Herrick AL. Contemporary management of Raynaud's phenomenon and digital ischaemic complications. Curr Opin Rheumatol 2011;23:555-61.

16. Pittenger MF, Mackay AM, Beck SC, et al. Multilineage potential of adult human mesenchymal stem cells. Science 1999;284:143-7.

17. Liew A, O'Brien T, O'Brien T. Therapeutic potential for mesenchymal stem cell transplantation in critical limb ischemia. Stem Cell Res Ther 2012;3:28.

18. Kinnaird T, Stabile E, Burnett MS, et al. Local delivery of marrowderived stromal cells augments collateral perfusion through paracrine mechanisms. Circulation 2004;109:1543-9.

19. Bronckaers A, Hilkens P, Martens W, et al. Mesenchymal stem/ stromal cells as a pharmacological and therapeutic approach to accelerate angiogenesis. Pharmacol Ther 2014;143:181-96.

20. Griffin MD, Ritter T, Mahon BP. Immunological aspects of allogeneic mesenchymal stem cell therapies. Hum Gene Ther 2010;21:1641-55.

21. Wan J, Xia L, Liang W, et al. Transplantation of bone marrow-derived mesenchymal stem cells promotes delayed wound healing in diabetic rats. J Diabetes Res 2013;2013:1-11.

22. Smith AN, Willis E, Chan VT, et al. Mesenchymal stem cells induce dermal fibroblast responses to injury. Exp Cell Res 2010;316:48-54.

23. Duffy GP, Ahsan T, O'Brien T, et al. Bone marrow-derived mesenchymal stem cells promote angiogenic processes in a time- and dose-dependent manner in vitro. Tissue Eng Part $A$ 2009;15:2459-70.

24. Elman JS, Murray RC, Murray RM, et al. Pharmacokinetics of natural and engineered secreted factors delivered by mesenchymal stromal cells. PLoS One 2014;9:e89882.

25. Uccelli A, Moretta L, Pistoia V. Immunoregulatory function of mesenchymal stem cells. Eur J Immunol 2006;36:2566-73.

26. Maxson S, Lopez EA, Yoo D, et al. Concise review: role of mesenchymal stem cells in wound repair. Stem Cells Trans/ Med 2012;1:142-9.

27. Shen $Q$, Chen $B$, Xiao Z, et al. Paracrine factors from mesenchymal stem cells attenuate epithelial injury and lung fibrosis. Mol Med Rep 2015;11:1.

28. Chen L, Tredget EE, Liu C, et al. Analysis of allogenicity of mesenchymal stem cells in engraftment and wound healing in mice. PLoS One 2009;4:e7119.

29. Dash NR, Dash SN, Routray P, et al. Targeting nonhealing ulcers of lower extremity in human through autologous bone marrow-derived mesenchymal stem cells. Rejuvenation Res 2009;12:359-66.

30. Debin L, Youzhao J, Ziwen L, et al. Autologous transplantation of bone marrow mesenchymal stem cells on diabetic patients with lower limb ischemia. J Med Coll PLA 2008;23:106-15.

31. Lu D, Chen B, Liang Z, et al. Comparison of bone marrow mesenchymal stem cells with bone marrow-derived mononuclear cells for treatment of diabetic critical limb ischemia and foot ulcer: a double-blind, randomized, controlled trial. Diabetes Res Clin Pract 2011:92:26-36

32. Iwase T, Nagaya N, Fujii T, et al. Comparison of angiogenic potency between mesenchymal stem cells and mononuclear cells in a rat model of hindlimb ischemia. Cardiovasc Res 2005;66:543-51.

33. Kim SW, Han H, Chae GT, et al. Successful stem cell therapy using umbilical cord blood-derived multipotent stem cells for Buerger's disease and ischemic limb disease animal model. Stem Cells 2006;24:1620-6.

34. Gupta PK, Chullikana A, Parakh R, et al. A double blind randomized placebo controlled phase I/II study assessing the safety and efficacy of allogeneic bone marrow derived mesenchymal stem cell in critical limb ischemia. J Trans/ Med 2013;11:143.

35. van Rhijn-Brouwer FC, Gremmels H, Fledderus JO, et al. Cellular therapies in systemic sclerosis: recent progress. Curr Rheumatol Rep 2016;18:12.

36. Christopeit M, Schendel M, Föll J, et al. Marked improvement of severe progressive systemic sclerosis after transplantation of mesenchymal stem cells from an allogeneic haploidentical-related donor mediated by ligation of CD137L. Leukemia 2008;22:1062-4.

37. Keyszer G, Christopeit M, Fick S, et al. Treatment of severe progressive systemic sclerosis with transplantation of mesenchymal stromal cells from allogeneic related donors: report of five cases. Arthritis Rheum 2011;63:2540-2.

38. Hare JM, Fishman JE, Gerstenblith G, et al. Comparison of allogeneic vs autologous bone marrow-derived mesenchyma stem cells delivered by transendocardial injection in patients with ischemic cardiomyopathy: the POSEIDON randomized trial. JAMA 2012;308:2369-79.

39. Conget P, Rodriguez F, Kramer S, et al. Replenishment of type VII collagen and re-epithelialization of chronically ulcerated skin after intradermal administration of allogeneic mesenchymal stromal cells in two patients with recessive dystrophic epidermolysis bullosa. Cytotherapy 2010;12:429-31.

40. Molendijk I, Bonsing BA, Roelofs $\mathrm{H}$, et al. Allogeneic bone marrowderived mesenchymal stromal cells promote healing of refractory perianal fistulas in patients with crohn's disease. Gastroenterology 2015;149:918-27.

41. Liang J, Zhang H, Hua B, et al. Allogenic mesenchymal stem cells transplantation in refractory systemic lupus erythematosus: a pilot clinical study. Ann Rheum Dis 2010;69:1423-9.

42. Allanore $\mathrm{Y}$, Denton $\mathrm{CP}$, Krieg $\mathrm{T}$, et al. Clinical characteristics and predictors of gangrene in patients with systemic sclerosis and digital ulcers in the Digital Ulcer Outcome Registry: a prospective, observational cohort. Ann Rheum Dis 2016;75:1736-40.

43. Silva I, Almeida J, Vasconcelos C. A PRISMA-driven systematic review for predictive risk factors of digital ulcers in systemic sclerosis patients. Autoimmun Rev 2015;14:140-52.

44. Teraa M, Sprengers RW, Schutgens RE, et al. Effect of repetitive intra-arterial infusion of bone marrow mononuclear cells in patients with no-option limb ischemia: the randomized, double-blind, placebo-controlled Rejuvenating Endothelial Progenitor Cells via Transcutaneous Intra-arterial Supplementation (JUVENTAS) trial. Circulation 2015;131:851-60.

45. Hare JM, Sanina C. Bone marrow mononuclear cell therapy and granulocyte colony-stimulating factor for acute myocardial infarction: is it time to reconsider? J Am Coll Cardiol 2015;65:2383-7.

46. Niemansburg SL, Teraa M, Hesam H, et al. Stem cell trials for cardiovascular medicine: ethical rationale. Tissue Eng Part $A$ 2014;20:2567-74.

47. Huang XP, Sun Z, Miyagi $Y$, et al. Differentiation of allogeneic mesenchymal stem cells induces immunogenicity and limits their long-term benefits for myocardial repair. Circulation 2010;122:2419-29.

48. Cipriani P, Guiducci S, Miniati I, et al. Impairment of endothelial cell differentiation from bone marrow-derived mesenchymal stem cells: new insight into the pathogenesis of systemic sclerosis. Arthritis Rheum 2007;56:1994-2004.

49. Cipriani P, Marrelli A, Benedetto PD, et al. Scleroderma mesenchymal stem cells display a different phenotype from healthy controls: implications for regenerative medicine. Angiogenesis 2013;16:595-607.

50. Guiducci S, Manetti M, Romano E, et al. Bone marrow-derived mesenchymal stem cells from early diffuse systemic sclerosis exhibit a paracrine machinery and stimulate angiogenesis in vitro. Ann Rheum Dis 2011:70:2011-21.

51. Vanneaux V, Farge-Bancel D, Lecourt S, et al. Expression of transforming growth factor $\beta$ receptor II in mesenchymal stem cells from systemic sclerosis patients. BMJ Open 2013;3:e001890.

52. Schwarz TM, Leicht SF, Radic T, et al. Vascular incorporation of endothelial colony-forming cells is essential for functional recovery 
of murine ischemic tissue following cell therapy. Arterioscler Thromb Vasc Biol 2012;32:e13-21.

53. Shabbir A, Zisa D, Suzuki G, et al. Heart failure therapy mediated by the trophic activities of bone marrow mesenchymal stem cells: a noninvasive therapeutic regimen. Am J Physiol Heart Circ Physiol 2009;296:H1888-97.

54. Schrepfer S, Deuse T, Reichenspurner $\mathrm{H}$, et al. Stem cell transplantation: the lung barrier. Transplant Proc 2007;39:573-6.

55. Gholamrezanezhad A, Mirpour S, Bagheri M, et al. In vivo tracking of $111 \mathrm{ln}$-oxine labeled mesenchymal stem cells following infusion in patients with advanced cirrhosis. Nucl Med Biol 2011;38:961-7.

56. Comerota AJ, Link A, Douville J, et al. Upper extremity ischemia treated with tissue repair cells from adult bone marrow. J Vasc Surg 2010;52:723-9.

57. Koshikawa M, Shimodaira S, Yoshioka T, et al. Therapeutic angiogenesis by bone marrow implantation for critical hand ischemia in patients with peripheral arterial disease: a pilot study. Curr Med Res Opin 2006;22:793-8.

58. Takagi G, Miyamoto M, Tara S, et al. Therapeutic vascular angiogenesis for intractable macroangiopathy-related digital ulcer in patients with systemic sclerosis: a pilot study. Rheumatology 2014;53:854-9.

59. Gremmels $\mathrm{H}$, Teraa M, Quax $\mathrm{PH}$, et al. Neovascularization capacity of mesenchymal stromal cells from critical limb ischemia patients is equivalent to healthy controls. Mol Ther 2014;22:1960-70.

60. Chung L, Denton CP, Distler O, et al. Clinical trial design in scleroderma: where are we and where do we go next? Clin Exp Rheumatol 2012;30:S97-102.

61. Khanna D, Furst DE, Allanore $\mathrm{Y}$, et al. Twenty-two points to consider for clinical trials in systemic sclerosis, based on EULAR standards. Rheumatology 2015:54

62. Matucci-Cerinic M, Seibold JR. Digital ulcers and outcomes assessment in scleroderma. Rheumatology 2008;47(Suppl 5):v46-7.

63. Bhedi A, Saxena AK, Gadani R, et al. Digital photography and transparency-based methods for measuring wound surface area. Indian J Surg 2013;75:111-4.

64. Rajbhandari SM, Harris ND, Sutton M, et al. Digital imaging: an accurate and easy method of measuring foot ulcers. Diabet Med 1999;16:339-42.

65. Smith V, Pizzorni C, De Keyser F, et al. Reliability of the qualitative and semiquantitative nailfold videocapillaroscopy assessment in a systemic sclerosis cohort: a two-centre study. Ann Rheum Dis 2010;69:1092-6.

66. Cutolo M, Sulli A, Pizzorni C, et al. Nailfold videocapillaroscopy assessment of microvascular damage in systemic sclerosis. $J$ Rheumatol 2000;27:155-60.
67. Ishigatsubo $\mathrm{Y}$, Ihata $\mathrm{A}$, Kobayashi $\mathrm{H}$, et al. Therapeutic angiogenesis in patients with systemic sclerosis by autologous transplantation of bone-marrow-derived cells. Mod Rheumatol 2010;20:263-72.

68. Hettema ME, Zhang D, Stienstra Y, et al. No effects of bosentan on microvasculature in patients with limited cutaneous systemic sclerosis. Clin Rheumatol 2009;28:825-33.

69. Khanna D, Berrocal VJ, Giannini EH, et al. The American College of Rheumatology provisional composite response index for clinical trials in early diffuse cutaneous systemic sclerosis. Arthritis Rheumatol 2016;68:299-311.

70. Kolahi J, Bang H, Park J. Towards a proposal for assessment of blinding success in clinical trials: up-to-date review. Community Dent Oral Epidemiol 2009;37:477-84.

71. Takahashi M, Izawa A, Ishigatsubo Y, et al. Therapeutic neovascularization by the implantation of autologous mononuclear cells in patients with connective tissue diseases. Curr Pharm Des 2009;15:2778-83.

72. Granel B, Daumas A, Jouve E, et al. Safety, tolerability and potential efficacy of injection of autologous adipose-derived stromal vascular fraction in the fingers of patients with systemic sclerosis: an openlabel phase I trial. Ann Rheum Dis 2015;74.

73. Scuderi N, Ceccarelli S, Onesti MG, et al. Human adipose-derived stromal cells for cell-based therapies in the treatment of systemic sclerosis. Cell Transplant 2013;22:779-95.

74. Del Papa N, Di Luca G, Sambataro D, et al. Regional implantation of autologous adipose tissue-derived cells induces a prompt healing of long-lasting indolent digital ulcers in patients with systemic sclerosis. Cell Transplant 2015;24.

75. Bene MD, Pozzi MR, Rovati L, et al. Autologous fat grafting for scleroderma-induced digital ulcers. An effective technique in patients with systemic sclerosis. Handchir Mikrochir Plast Chir 2014;46:242-7.

76. Nevskaya T, Ananieva L, Bykovskaia S, et al. Autologous progenitor cell implantation as a novel therapeutic intervention for ischaemic digits in systemic sclerosis. Rheumatology 2009;48:61-4.

77. Guiducci S, Distler O, Distler JH, et al. Mechanisms of vascular damage in SSc--implications for vascular treatment strategies. Rheumatology 2008;47(Suppl 5):v18-20.

78. Taylor PL, Barker RA, Blume KG, et al. Patients beware: commercialized stem cell treatments on the web. Cell Stem Cell 2010;7:43-9.

79. Daley GQ. Polar extremes in the clinical use of stem cells. N Engl J Med 2017;376:1075-7. 